\title{
Collecting Laboratory
}

National Cancer Institute

\section{Source}

National Cancer Institute. Collecting Laboratory. NCI Thesaurus. Code C93405.

The laboratory that collects the specimen from a study subject. 